\title{
Exploring the Impact of Network Structure and Demand Collaboration on the Dynamics of a Supply Chain Network Using a Robust Control Approach
}

\author{
Yongchang Wei, ${ }^{1}$ Hongwei Wang, ${ }^{2}$ and Fangyu Chen ${ }^{1}$ \\ ${ }^{1}$ School of Business Administration and the Center of Industrial Economy Research, Zhongnan University of Economics and Law, \\ Wuhan 430073, China \\ ${ }^{2}$ Institute of Systems Engineering, The Key Laboratory of Image Processing and Intelligent Control of Education Ministry, Huazhong \\ University of Science and Technology, Wuhan 430074, China
}

Correspondence should be addressed to Hongwei Wang; hwwang@mail.hust.edu.cn

Received 21 August 2015; Accepted 4 October 2015

Academic Editor: Michael Z. Q. Chen

Copyright (c) 2015 Yongchang Wei et al. This is an open access article distributed under the Creative Commons Attribution License, which permits unrestricted use, distribution, and reproduction in any medium, provided the original work is properly cited.

\begin{abstract}
A supply chain network might exhibit complex dynamics in the face of increasingly volatile and uncertain environment. The impact of network structure and collaboration on the dynamics and robustness of supply chain network, however, remains to be explored. In this paper, a unified state space model for a two-layer supply chain network composed of multiple distributors and multiple retailers is developed. A robust control algorithm is advocated to reduce both order and demand fluctuations for unknown demand. Numerical simulations demonstrate that the robust control approach has the advantage to reduce both inventory and order fluctuations. In the simulation experiment, it is interesting to notice that complex network structure and collaborations might contribute to the reduction of inventory and order oscillations. This paper yields new insights into the overestimated bullwhip effect problem and helps us understand the complexities of supply chain networks.
\end{abstract}

\section{Introduction}

A supply chain network is referred to as a complex network of organizations that synchronizes a series of interrelated business processes, such as procurement, manufacturing, distribution, and retailing, to create values to final customers in the form of products and services [1]. In reality, supply chain network is facing more and more fluctuating market environment and the customer demand is usually badly uncertain due to a lot of factors, such as technology revolution, short product cycles, and promotions. These uncertainties might propagate and further lead to unexpected dynamic behaviors, for example, instability [2-5], bullwhip effect [6-9], and even chaos [10-12], which can further cause huge extra costs due to order and inventory fluctuations [13]. Therefore, it is increasingly important to understand the dynamics and improve the robustness before designing a supply chain network.
It has been found that supply chain network has scalefree and small-world features [14]. Note that the small-world feature and scaleless feature have been widely explored in complex network theory [15-17]. These features indicate that a handful of nodes might dominate the whole network and potentially enhance the capability to respond to uncertainties. In addition, determining the number of upstream suppliers and extending distribution channels to gain more market shares are also important topics in supply chain management. All these facts demonstrate that the topology of supply chain network has substantial impacts on overall performance. In fact, the supply chain network studied in this paper is also a networked control system. Similar to the literature stream of networked control system [18-20], the network structure is a significant factor that affects the control performance. In addition, the central task for the supply chain network or the networks studied in the previous literature is how to design an appropriate controller to ensure stability and 
satisfy specific requirements. It is worthwhile to notice that a supply chain network is usually composed of heterogeneous nodes, for example, retailers, distributors, manufacturers, and raw material suppliers. In a supply chain network, distributors usually exchange information, for example, placing and receiving orders, with nodes inside the network. Unlike distributors, retailers, however, must fulfill customer demands from external volatile environment. For this reason, the dynamics of heterogeneous nodes should be treated or described differently. Furthermore, there exist a lot of interaction activities among nodes in supply chain network, for example, cooperations and competitions. As a result, all these features, complex topologies caused by complex supply relationships, heterogeneous nodes, and interactions, make supply chain network increasingly complex, hard to describe, and challenging for exploring dynamics and robustness.

It is not surprising that the dynamics and robustness of supply chain system have received considerable attention over the past decade. Control engineering technologies are frequently used to analyze stability $[2,21,22]$ and study the bullwhip effect [7, 8, 23-25], which refers to the amplification of order fluctuations as one moves up a supply chain from downstream to upstream $[6,26]$. In particular, robust control methods are well used in analyzing the bullwhip effect for known inventory rules [9, 27], or designing inventory rules for unknown demand using feedback control method [28]. Some "fluid models" and simulation models are also proposed to study the dynamic properties of supply chain systems $[3,10,29,30]$.

The majority of the previous studies focus on serial supply chains. Most supply chain systems, however, have a network topology in which each entity's decision may be influenced directly or indirectly by other nodes. More importantly, demand may arise from many customers at different locations of the supply chain network, and the interactions among nodes should be addressed. Unfortunately, few studies are undertaken to address the dynamics, robustness, and the impact of collaborations on dynamics in the context of supply chain network. For example, Helbing [31] proposes a rather general model of supply chain network and connected it to queueing theory and macroeconomics. Scholz-Reiter et al. [32] presented an approach to calculate the stability condition by mathematical system theory to guarantee stability for production networks, to identify a stability region, and to refine the region by discrete event simulations. Ouyang and Li [33] study the bullwhip effect propagation in a supply chain network with linear and time-invariant inventory management policies using a frequency domain control method. They obtained conditions to predict the existence of bullwhip effect for unknown demand. Recently, Dominguez et al. [34] study the bullwhip effect of a divergent supply chain system with simulation experiment. They begin to notice that complex structure of supply chain might yield different bullwhip effect conclusions.

From the above, the dynamics of supply chain network has attracted the attention in the very recent years. The impact of network structure and collaboration on supply chain dynamics still remain unclear. The contributions of this paper are as follows. A unified state space model is developed to model the dynamic for a supply chain network composed of heterogeneous nodes. To improve the robustness for unknown demand, a robust $H_{\infty}$ control approach is advocated to obtain optimal inventory rules. The time domain robust control method facilitates us to obtain the optimal replenishment policy under well-defined performance measures, in order to reduce both order and inventory fluctuations. There is a trade-off between reducing inventory variations and mitigating the bullwhip effect [23]. The effectiveness and superiority of the proposed method are numerically validated for several demand processes. Furthermore, we incorporate the network topology and demand collaboration between retailers into the dynamic model, which enables us to numerically study the impacts of network structure and demand collaboration on dynamics improvement. We show that both demand collaboration and complex supply relationship might contribute to dynamics improvement. The results obtained in this research provide new insights into supply chain management, especially for the overestimated bullwhip effect problem $[35,36]$, via considering complex supply relationship and demand collaboration.

The structure of this paper is arranged as follows. Section 2 describes the model and Section 3 introduces a robust metric and the optimization algorithm to calculate the minimal value of the robust metric. In Section 4 , we numerically validate the effectiveness of the robust control method and also study the influences of network structure and demand collaboration on dynamics and robustness.

\section{Modeling the Supply Chain Network}

Consider a two-layer supply chain network constituted with $m$ distributors and $n$ retailers. The structure of supply chain network is shown in Figure 1. Without loss of generality, we impose the following assumptions on the supply chain network:

(i) All the facilities, including retailers and distributors, have the same events order in each period, in order to construct a discrete-time state space model. They place replenishment orders at the beginning of each period and fulfill downstream orders or demands during the remaining time.

(ii) Each retailer might choose to place orders from many distributors and each distributor might satisfy the order from multiple retailers. All the distributors place orders from external suppliers.

(iii) The customer demands of retailers that come from external market are uncertain. All the nodes in the supply chain network follow the same way to deal with shortages; namely, unfulfilled orders or demands will be backlogged.

(iv) Both the distributors and retailers have fixed replenishment lead times.

Denote symbols $i, 1 \leq i \leq m$, and $j, 1 \leq j \leq n$, as the $i$ th distributor and the $j$ th retailer, respectively. Then the supply relationship between retailers and distributors could 


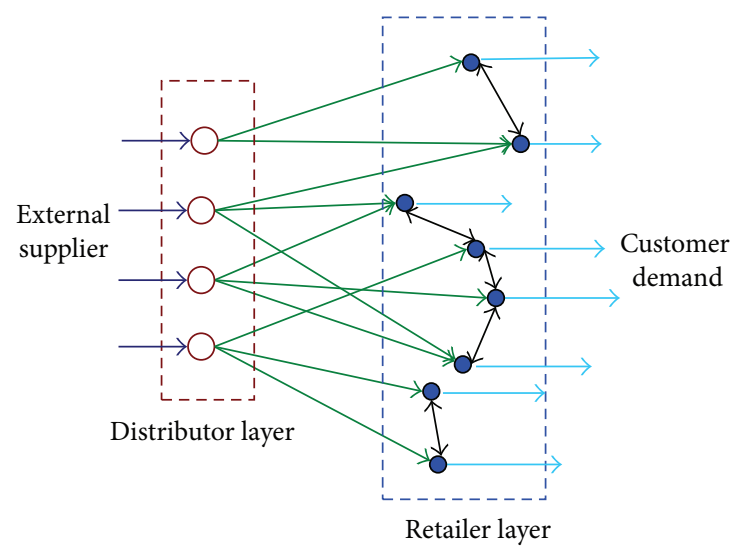

FIGURE 1: The structure of a general two-layer supply chain network.

be defined by a supply relationship matrix $L=\left(l_{i j}\right)_{m \times n} \in R^{m \times n}$. If $l_{i j}=1$, the distributor $i$ and the retailer $j$ establish the supply relationship between them. Otherwise, if $l_{i j}=0$, there is no relationship between them. In fact, the supply relationship matrix reflects the network topology. For example, if each column of the matrix $L$ has only one element with value 1 , then each retailer has only one immediate supplier. In contrast, if $l_{i j}=1(\forall i, j)$, then each distributor supplies goods to every retailer, which represents the most complex network structure.

Suppose that the retailers in the same market can collaborate with each other, and consider the collaboration mechanism via demand diversion in [33]. Let $d_{j}(t)$ be the demand received by retailer $j$. Then the amount $\delta_{j_{1} j_{2}} \times$ $\left[d_{j_{1}}(t)-d_{j_{2}}(t)\right]$ of the received demand of retailer $j_{1}$ will be satisfied by retailer $j_{2}$ if $d_{j_{1}}(t)>d_{j_{2}}(t)$. Note that the parameter $\delta_{j_{1} j_{2}}$ can be negotiated by each pair of retailers by considering some factors such as geographic location and demand characteristics. As a result, we can define a collaboration matrix $H \triangleq\left(\delta_{j_{1} j_{2}}\right)_{n \times n} \in R^{n \times n}$ to exactly describe the demand diversion among retailers in the supply chain network. Assume that the demand of retailer $j_{1}$ is $d_{j_{1}}(t)$ and the demand of retailer $j_{2}$ is $d_{j_{2}}(t)$. The essential demand of retailer $j_{1}$ after demand collaboration becomes $d_{j_{1}}(t)+$ $\delta_{j_{1} j_{2}}\left[d_{j_{2}}(t)-d_{j_{1}}(t)\right]$. The demand of retailer $j_{2}$ is changed to $d_{j_{2}}(t)+\delta_{j_{2} j_{1}}\left[d_{j_{1}}(t)-d_{j_{2}}(t)\right]$. Then we must have $\delta_{j_{1} j_{2}}=\delta_{j_{2} j_{1}}$ without losing any customer demand. In other words, the collaboration matrix is symmetric in order to balance the shifted demand between each pair of retailers.

As the supply chain network is composed of heterogeneous nodes, the dynamic equations for the retailers and distributors should be described separately. We will now first consider the inventory dynamics for distributors. Let $w_{i}(t)$, $1 \leq i \leq m$, denote the inventory position of the distributor $i$, let $u_{i}(t)$ denote the placed order by distributor $i$ from external suppliers, and let $u_{i j}(t)$ denote the received order of distributor $i$ from retailer $j(1 \leq j \leq n)$. Then, the resulting dynamics of the distributor $i$ can be represented by

$$
w_{i}(t+1)=w_{i}(t)+u_{i}(t)-\sum_{j=1}^{n} l_{i j} u_{i j}(t)
$$

All the retailers not only place orders from their upstream distributors but also fulfill external customer demand. In addition, a retailer might divert its received demand to its collaboration partner. Let $r_{j}(t), 1 \leq j \leq n$, denote the inventory position of retailer $j$; then its balanced inventory equation could be obtained as

$$
\begin{aligned}
r_{j}(t+1)= & r_{j}(t)+\sum_{i=1}^{m} l_{i j} u_{i j}(t)-d_{j}(t) \\
& -\sum_{j_{1}=1}^{n} \delta_{j j_{1}}\left[d_{j_{1}}(t)-d_{j}(t)\right] .
\end{aligned}
$$

It is worthwhile to note that as we select inventory position as the state variable, the lead time disappeared in the dynamics equation. In fact, inventory position is a comprehensive variable that incorporates on-hand inventory, backorder, and on-road inventory simultaneously.

In order to develop a unified state space model, we will now transform the supply relationship matrix $L$ and the collaboration matrix $H$. By doing this, we can incorporate the network structure and collaboration among retailers into the dynamic model. Let $L_{j}=\left[l_{1 j}, l_{2 j}, \ldots, l_{m j}\right]^{\prime}, 1 \leq j \leq n$, define the $j$ th column of the matrix $L$. Then we could define the following two matrixes:

$$
\begin{aligned}
& M_{1} \triangleq \operatorname{diag}\left(L_{1}^{\prime}, L_{2}^{\prime}, \ldots, L_{n}^{\prime}\right), \\
& M_{2} \triangleq\left[\begin{array}{llll}
G_{1} & G_{2} & \cdots & G_{n}
\end{array}\right],
\end{aligned}
$$

where $G_{j}=\operatorname{diag}\left(l_{1 j}, l_{2 j}, \ldots, l_{m j}\right), 1 \leq j \leq n$. We see that $M_{1} \in$ $R^{n \times m n}$ and $M_{2} \in R^{m \times m n}$. Based on the collaboration matrix $H$, we could obtain the following matrix:

$$
H_{L} \triangleq\left[\begin{array}{cccc}
1-\sum_{j \neq 1} \delta_{1 j} & \delta_{12} & \cdots & \delta_{1 n} \\
\delta_{21} & 1-\sum_{j \neq 2} \delta_{2 j} & \cdots & \delta_{2 n} \\
\cdots & \cdots & \cdots & \cdots \\
\delta_{n 1} & \delta_{n 2} & \cdots & 1-\sum_{j \neq n} \delta_{n j}
\end{array}\right] .
$$


The demand rate of retailer $j$ is assumed to take the form

$$
d_{j}(t)=d_{j}^{e}+\xi_{j}(t)
$$

where $d_{j}^{e}$ is a known constant and $\xi_{j}(t)$ denotes the energy bounded disturbance with mean 0 . The demand in Ouyang and Daganzo [9] and Ouyang and Li [33] also has the characteristics of the above demand pattern. If the supply chain network is stable and $d_{j}(t)=d_{j}^{e}, j=1,2, \ldots, n$, then the inventory positions and order quantities of retailers and distributors will return to constant or steady values after finite periods. Define $w_{i}^{e}$ and $r_{j}^{e}$ as the steady values of inventory position of distributor $i$ and retailer $j$, respectively. Let $u_{i}^{e}$ and $u_{i j}^{e}$ denote the steady values of the amount of order of the distributor $i$ placed from external suppliers and the amount of order of the retailer $j$ placed from distributor $i$, respectively. In such case, we can have $\lim _{t \rightarrow \infty} w_{i}(t)=w_{i}^{e}, \lim _{t \rightarrow \infty} r_{j}(t)=$ $r_{j}^{e}, \lim _{t \rightarrow \infty} u_{i}(t)=u_{i}^{e}$, and $\lim _{t \rightarrow \infty} u_{i j}(t)=u_{i j}^{e}$.

It is well-known that inventory rules play significant roles in determining supply chain dynamics. In fact, inventory rules are essentially feedback controllers using state information, for example, inventory position. Define the following state vector: $\widetilde{x}(t)=\left[\begin{array}{ll}\widetilde{w}(t) & \widetilde{r}(t)\end{array}\right]^{\prime}$, where

$$
\begin{aligned}
\widetilde{w}(t) & =\left[\widetilde{w}_{1}(t), \widetilde{w}_{2}(t), \ldots, \widetilde{w}_{m}(t)\right] \\
& =\left[w_{1}(t)-w_{1}^{e}, w_{2}(t)-w_{2}^{e}, \ldots, w_{m}(t)-w_{m}^{e}\right], \\
\widetilde{r}(t) & =\left[\widetilde{r}_{1}(t), \widetilde{r}_{2}(t), \ldots, \widetilde{r}_{n}(t)\right] \\
& =\left[r_{1}(t)-r_{1}^{e}, r_{2}(t)-r_{2}^{e}, \ldots, r_{n}(t)-r_{n}^{e}\right] .
\end{aligned}
$$

The input vector can be represented by

$$
\begin{aligned}
\tilde{d}(t) & =\left[\tilde{d}_{1}(t), \tilde{d}_{1}(t), \ldots, \tilde{d}_{n}(t)\right]^{\prime} \\
& =\left[d_{1}(t)-d_{1}^{e}, d_{2}(t)-d_{2}^{e}, \ldots, d_{n}(t)-d_{n}^{e}\right]^{\prime} \in R^{n} .
\end{aligned}
$$

Before defining the control vector, we will now introduce the operator $\operatorname{Vec}(A)$.

Definition 1. Assume that $A \in R^{m \times n}$ is a matrix with $m$ rows and $n$ columns and $A=\left(A_{1}, A_{2}, \ldots, A_{n}\right)$, where $A_{i}$ is the $i$ th column of $A$. Then we can produce a single column vector using the following operator, which is given by

$$
\operatorname{Vec}(A)=\left[A_{1}^{\prime}, A_{2}^{\prime}, \ldots, A_{n}^{\prime}\right]^{\prime} \in R^{m n}
$$

For the supply chain network, the control vector $\widetilde{u}(t)$ can be represented as $\widetilde{u}(t)=\left[\begin{array}{ll}\widetilde{u}_{w}(t) & \widetilde{u}_{r}(t)\end{array}\right]^{\prime} \in R^{m+m n}$, where

$$
\begin{aligned}
\tilde{u}_{w}(t) & =\left[\tilde{u}_{1}(t), \tilde{u}_{2}(t), \ldots, \widetilde{u}_{m}(t)\right] \\
& =\left[u_{1}(t)-u_{1}^{e}, u_{2}(t)-u_{2}^{e}, \ldots, u_{m}(t)-u_{m}^{e}\right], \\
\tilde{u}_{r}(t) & =\operatorname{Vec}\left(M_{R}(t)\right)^{\prime},
\end{aligned}
$$

where

$$
\begin{aligned}
& M_{R}(t)=\left[\begin{array}{cccc}
\tilde{u}_{11}(t) & \tilde{u}_{12}(t) & \cdots & \tilde{u}_{1 n}(t) \\
\tilde{u}_{21}(t) & \tilde{u}_{22}(t) & \cdots & \tilde{u}_{2 n}(t) \\
\cdots & \cdots & \cdots & \cdots \\
\tilde{u}_{m 1}(t) & \tilde{u}_{m 2}(t) & \cdots & \tilde{u}_{m n}(t)
\end{array}\right] \\
& =\left[\begin{array}{cccc}
u_{11}(t)-u_{11}^{e} & u_{12}(t)-u_{12}^{e} & \cdots & u_{1 n}(t)-u_{1 n}^{e} \\
u_{21}(t)-u_{21}^{e} & u_{22}(t)-u_{22}^{e} & \cdots & u_{2 n}(t)-u_{2 n}^{e} \\
\cdots & \cdots & \cdots & \cdots \\
u_{m 1}(t)-u_{m 1}^{e} & u_{m 2}(t)-u_{m 2}^{e} & \cdots & u_{m n}(t)-u_{m n}^{e}
\end{array}\right] \\
& \in R^{m \times n} .
\end{aligned}
$$

Define $\tilde{y}(t) \in R^{2 m+n+m n}$ as system output and let $I_{x}$ denote the unit matrix with $x$ dimensions. We then can develop the following unified state space model:

$$
\begin{aligned}
\tilde{x}(t+1) & =\tilde{x}(t)+B \tilde{u}(t)+B_{w} \tilde{d}(t), \\
\tilde{y}(t) & =C \tilde{x}(t)+D \tilde{u}(t),
\end{aligned}
$$

where

$$
\begin{aligned}
B & =\left[\begin{array}{cc}
I_{m} & -M_{2} \\
0 & M_{1}
\end{array}\right] \in R^{(m+n) \times(m+m n)}, \\
B_{w} & =\left[\begin{array}{c}
0 \\
-H_{L}
\end{array}\right] \in R^{(m+n) \times n}, \\
C & =\left[\begin{array}{cc}
\chi_{i} I_{m+n} & 0 \\
0 & 0
\end{array}\right] \in R^{(2 m+n+m n) \times(m+n)}, \\
D & =\left[\begin{array}{cc}
0 & 0 \\
0 & \chi_{o} I_{m(n+1)}
\end{array}\right] \in R^{(2 m+n+m n) \times(m+m n)},
\end{aligned}
$$

in which $\chi_{i}$ and $\chi_{o}$ are variables with either value 1 or value 0 to define system output according to practical situations. For example, if managers only care for inventory fluctuations, they can set $\chi_{i}=1$ and $\chi_{o}=0$. Otherwise, the setting of $\chi_{i}=0$ and $\chi_{o}=1$ can be used to mitigate bullwhip effect or order fluctuations. Both the inventory and order dynamics will be considered if $\chi_{i}=1$ and $\chi_{o}=1$. Based on the state space model, we can design inventory rules to improve the dynamics and robustness of the supply chain network for unknown demand with robust $H_{\infty}$ control method.

\section{The Robust Performance Metric and $H_{\infty}$ Control Method}

The bullwhip effect, one kind of typical dynamic behavior, is of great significance and has been investigated extensively. The robustness of bullwhip effect, however, has been addressed recently only in a few literatures [9, 27, 28]. Meanwhile, most of the existing studies on the bullwhip effect pay major attention to order fluctuations but inventory fluctuations are neglected. To this end, this research focuses 
on improving the dynamics and robustness of supply chain system for unknown demand with a robust $H_{\infty}$ control approach with the aim to reduce both inventory and order fluctuations.

Based on the state space model (11), we will now consider the following robust metric:

$$
W_{I} \triangleq \sup _{\forall \widetilde{d}(t) \neq 0}\left[\frac{\sum_{k=0}^{\infty} \tilde{y}(t)^{\prime} \tilde{y}(t)}{\sum_{k=0}^{\infty} \tilde{d}(t)^{\prime} \tilde{d}(t)}\right]^{1 / 2}
$$

We see that the metric $W_{I}$ is the amplification metric of the worst-case root mean square errors (RMSE) when the customer demand is unknown. Therefore, minimizing the value of $W_{I}$ can effectively improve the dynamics and robustness of supply chain system. It is worthwhile to mention that this metric, also called $L_{2}$ gain or $H_{\infty}$ norm, has been widely used in the field of control engineering. Although it is not an economic metric, the metric $W_{I}$ is intimately related to fluctuations of order and inventory in supply chain systems. For example, Boukas [28] pointed out that reducing the value of the metric $W_{I}$ increases the speed of a simple production control system to respond to customer demand. Ouyang and Daganzo [9] directly used this metric to quantify the bullwhip effect for unknown demand.

From the form of formula (13), we see that reducing the value of metric $W_{I}$ reduces the fluctuation of system output for unknown input. Thus, we can reduce order oscillations if we select placed orders as system output by setting $\chi_{i}=0$ and $\chi_{o}=1$. However, in most cases, inventory fluctuations and order fluctuations should be balanced. Unlike the traditional bullwhip effect metric, which mainly focuses on dampening order fluctuations, the metric $W_{I}$ can take both order fluctuations and inventory fluctuations into account by setting $\chi_{i}=1$ and $\chi_{o}=1$. In this case, the exact formula of $W_{I}$ for our supply chain network model becomes

$$
W_{I}=\sup _{\forall \widetilde{d}(t) \neq 0}\left\{\frac{\sum_{t=1}^{\infty}\left\{\sum_{i=1}^{m}\left[\widetilde{w}_{i}(t)^{2}+\widetilde{u}_{i}(t)^{2}\right]+\sum_{j=1}^{n}\left[\widetilde{r}_{j}(t)^{2}+\sum_{i=1}^{m} \widetilde{u}_{i j}(t)^{2}\right]\right\}}{\sum_{t=1}^{\infty} \sum_{j=1}^{n} \widetilde{d}_{j}(t)^{2}}\right\}^{1 / 2} .
$$

As emphasized, minimizing the value of the metric $W_{I}$ helps improving dynamics for unknown demand. Here we focus on designing appropriate inventory rules to achieve this goal. In this research, the inventory rule for the supply chain network can be represented in the form of state feedback controller, which is given by $\widetilde{u}(t)=K \widetilde{x}(t)$. Then the robust $H_{\infty}$ control problem of our supply chain network model is to seek a feedback controller $\widetilde{u}(t)=K \widetilde{x}(t)$ that satisfies the following optimization problem:

$$
\min _{\forall \widetilde{u}(t)=K \widetilde{x}(t)} W_{I}
$$

The inventory rule to minimize the value of the robust metric $W_{I}$ for the state space model (11) can be obtained by Theorem 2. The proof process refers to Kim and Park [37].

Theorem 2. Consider the discrete-time system (11). If there exists a positive-definite matrix $Q$ and a matrix $M$ satisfies the following optimization problem:

$$
\min \gamma^{1 / 2}
$$

subject to

$$
\left[\begin{array}{cccc}
-Q & Q+B M & B_{w} & 0 \\
Q+M^{\prime} B^{\prime} & -Q & 0 & Q C^{\prime}+M^{\prime} D^{\prime} \\
B_{w}^{\prime} & 0 & -\gamma I_{n} & 0 \\
0 & C Q+D M & 0 & -I_{(2 m+n+m n)}
\end{array}\right]<0,
$$

then system (11) is quadratically stable and the minimal value of the robust metric $W_{I}$ can be approximated with the minimized $\gamma^{1 / 2}$, with the state-feedback controller: $\widetilde{u}(t)=M Q^{-1} \tilde{x}(t)$.
The importance of Theorem 2 lies in two aspects. Firstly, the stability of the whole supply chain network is warranted if the optimization problem in Theorem 2 is solvable. Secondly, it produces an inventory rule that minimizes the metric $W_{I}$, or the $H_{\infty}$ norm, for unknown demand to reduce output oscillations. It also should be noted that the optimization problem can be readily solved using the standard numerical software, MATLAB, which enables us to numerically study the impacts of demand collaborations and network structures on dynamics and robustness.

\section{Numerical Analysis}

As introduced, the proposed robust $H_{\infty}$ control method is expected to reduce both order and inventory fluctuations, which will be numerically validated in the following section. Meanwhile, as the network topology and collaboration among retailers have been incorporated into the unified state space model, it enables us to study the influences of network structures and collaborations on the improvement of dynamics and robustness.

Traditionally, inventory and order fluctuations haven been measured with variance or standard deviation. For example, the bullwhip effect can be quantified with the ratio of variance between demand and order [26]. Here we consider the following four metrics in the numerical analysis:

$$
\begin{aligned}
& W_{b 1}=\sum_{i=1}^{m} \operatorname{Var}\left(\widetilde{u}_{i}(t)\right), \\
& W_{b 2}=\sum_{i=1}^{m} \sum_{j=1}^{n} \operatorname{Var}\left(\tilde{u}_{i j}(t)\right),
\end{aligned}
$$




$$
\begin{aligned}
& W_{s 1}=\sum_{i=1}^{m} \operatorname{Var}\left(\widetilde{w}_{i}(t)\right), \\
& W_{s 2}=\sum_{j=1}^{n} \operatorname{Var}\left(\tilde{r}_{j}(t)\right),
\end{aligned}
$$

in which $\operatorname{Var}(\cdot)$ is used to calculate the variances of time sequences. It is quite apparent to see that the metrics $W_{b 1}$ and $W_{b 2}$, respectively, represent the order fluctuations at distributor layer and retailer layer. The latter two metrics $W_{s 1}$ and $W_{s 2}$ are used to measure the inventory oscillations for retailers and distributors.

4.1. Effectiveness Validation for the Robust Control Method. Consider a supply chain network composed of 3 retailers and 3 distributors. Without loss of generality, we assume that there exists no collaboration among retailers and each retailer places order from all the three distributors. The supply relationship matrix and collaboration matrix can be obtained as

$$
\begin{gathered}
L=\left[\begin{array}{lll}
1 & 1 & 1 \\
1 & 1 & 1 \\
1 & 1 & 1
\end{array}\right], \\
H=\left[\begin{array}{lll}
0 & 0 & 0 \\
0 & 0 & 0 \\
0 & 0 & 0
\end{array}\right] .
\end{gathered}
$$

Assume that the demand of each retailer follows the firstorder autoregressive process:

$$
\tilde{d}_{j}(t+1)=\rho \tilde{d}_{j}(t)+(1-\rho) \varepsilon_{t}, \quad j \in\{1,2,3\},
$$

in which $\rho$ is the autoregressive parameter and $\varepsilon_{t}$ is the white noise. Setting different values for $\chi_{i}$ and $\chi_{o}$, we can consider three different control ways:

(i) control way 1: to reduce inventory fluctuation $\left(\chi_{i}=1\right.$, $\left.\chi_{o}=0\right)$;

(ii) control way 2: to reduce order fluctuation $\left(\chi_{i}=0\right.$, $\left.\chi_{o}=1\right)$;

(iii) control way 3: to reduce both order and inventory fluctuations $\left(\chi_{i}=1, \chi_{o}=1\right)$.

Using the optimization algorithm in Theorem 2, we can obtain three different inventory rules for three control ways. Take the third control way as an example. In such a parameter setting, we have $\chi_{i}=1, \chi_{o}=1$. As we consider a supply chain network composed of 3 retailers and 3 distributors, we could have $n=m=3$. Then, the matrices $M_{1}$ and $M_{2}$ can be obtained as

$$
\begin{aligned}
& M_{1}=\left[\begin{array}{lllllllll}
1 & 1 & 1 & 0 & 0 & 0 & 0 & 0 & 0 \\
0 & 0 & 0 & 1 & 1 & 1 & 0 & 0 & 0 \\
0 & 0 & 0 & 0 & 0 & 0 & 1 & 1 & 1
\end{array}\right], \\
& M_{2}=\left[\begin{array}{lllllllll}
1 & 0 & 0 & 1 & 0 & 0 & 1 & 0 & 0 \\
0 & 1 & 0 & 0 & 1 & 0 & 0 & 1 & 0 \\
0 & 0 & 1 & 0 & 0 & 1 & 0 & 0 & 1
\end{array}\right] .
\end{aligned}
$$

Because we do not consider demand collaboration in this section, the matrix $H_{L}$ will be calculated as $H_{L}=\operatorname{diag}\{1,1,1\}$. From the value of $M_{1}, M_{2}$, and $H_{L}$, we can further easily calculate the matrices $B, B_{w}, C$, and $D$. The inventory rule, a state-feedback controller, can be solved using Theorem 2 with LMI Toolbox in MATLAB, which is represented as

$$
\tilde{u}(t)=\left[\begin{array}{ccccccc}
-0.4140 & -0.1911 & -0.1911 & -0.2656 & -0.2656 & -0.2656 \\
-0.1911 & -0.4140 & -0.1911 & -0.2656 & -0.2656 & -0.2656 \\
-0.1911 & -0.1911 & -0.4140 & -0.2656 & -0.2656 & -0.2656 \\
0.1450 & -0.0779 & -0.0779 & -0.3201 & -0.0058 & -0.0058 \\
-0.0779 & 0.1450 & -0.0779 & -0.3201 & -0.0058 & -0.0058 \\
-0.0779 & -0.0779 & 0.1450 & -0.3201 & -0.0058 & -0.0058 \\
0.1450 & -0.0779 & -0.0779 & -0.0058 & -0.3201 & -0.0058 \\
-0.0779 & 0.1450 & -0.0779 & -0.0058 & -0.3201 & -0.0058 \\
-0.0779 & -0.0779 & 0.1450 & -0.0058 & -0.3201 & -0.0058 \\
0.1450 & -0.0779 & -0.0779 & -0.0058 & -0.0058 & -0.3201 \\
-0.0779 & 0.1450 & -0.0779 & -0.0058 & -0.0058 & -0.3201 \\
-0.0779 & -0.0779 & 0.1450 & -0.0058 & -0.0058 & -0.3201
\end{array}\right] \tilde{x}(t)
$$

The inventory and order dynamics of the supply chain network with $\rho=0.6$ are shown in Figures 2 and 3. With a simulation length of 15000 periods and by using a standard numerical software, we can calculate the values of the four 


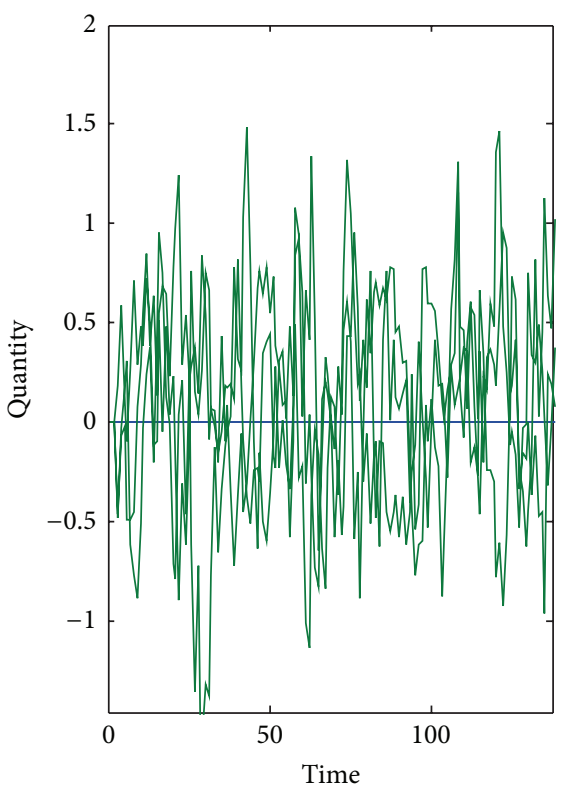

_ Inventory dynamics for retailers

_ Inventory dynamics for distributors

(a) Inventory curves under the first control way

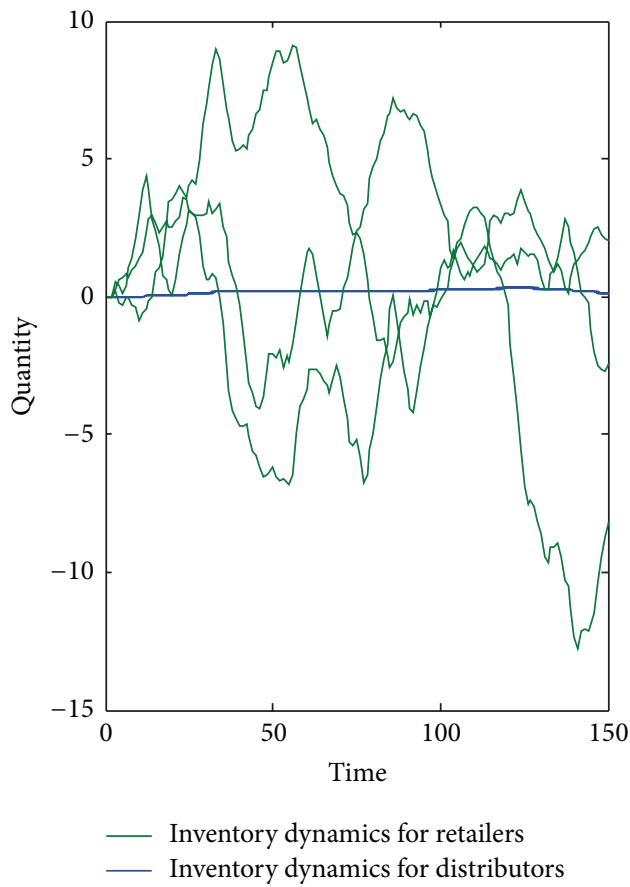

(b) Inventory curves under the second control way

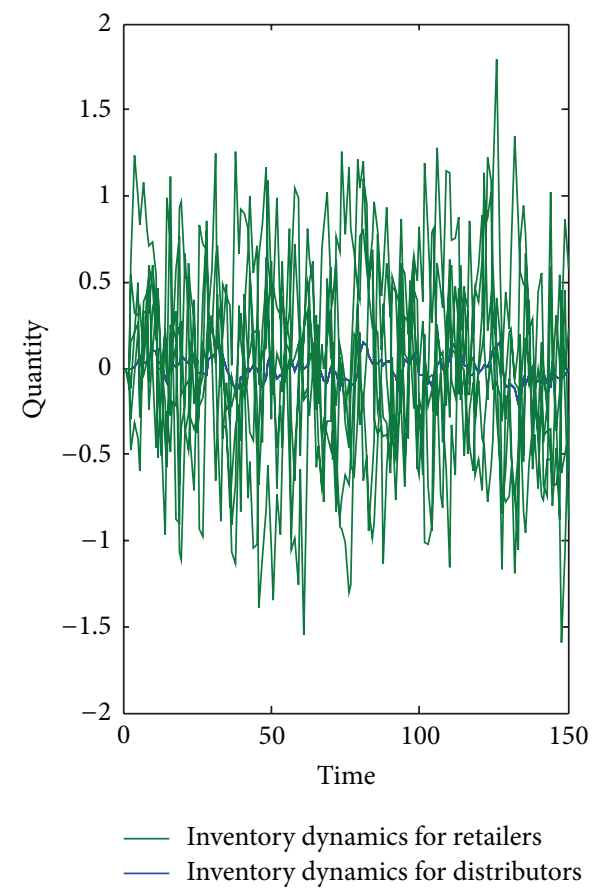

(c) Inventory curves under the third control way

Figure 2: Dynamic curves of inventory under three different control ways.

metrics, $W_{b 1}, W_{b 2}, W_{s 1}$, and $W_{s 2}$, which are summarized in Table 1.

From Table 1 and Figures 2 and 3, we see that the first control way has an obvious effect on reducing inventory fluctuations. However, it inevitably results in huge order fluctuations. The second control way, in contrast, behaves well in reducing order fluctuations at the expense of high inventory fluctuations. We see that there is an obvious tradeoff between improving inventory dynamics and damping order fluctuations. In fact, balancing inventory fluctuations and order fluctuation has been recognized as an important problem in the literature [23]. 


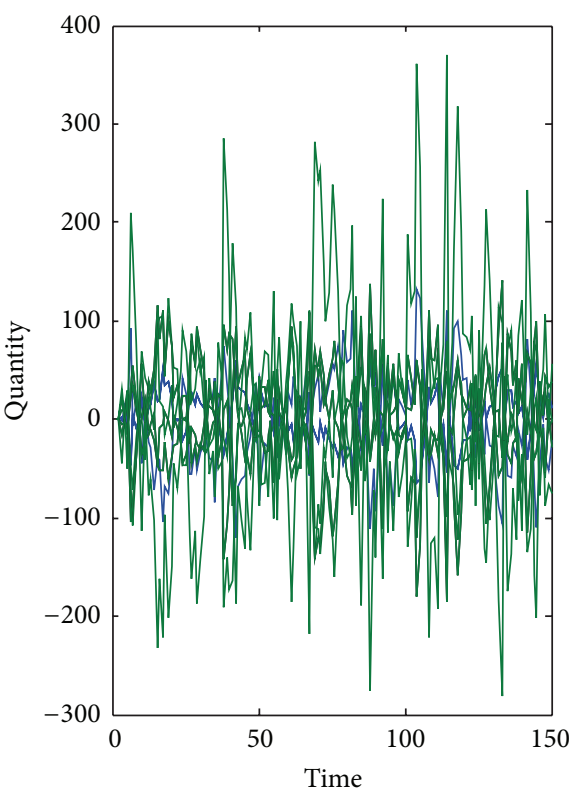

- Order dynamics for retailers Order dynamics for distributors

(a) Order curves under the first control way

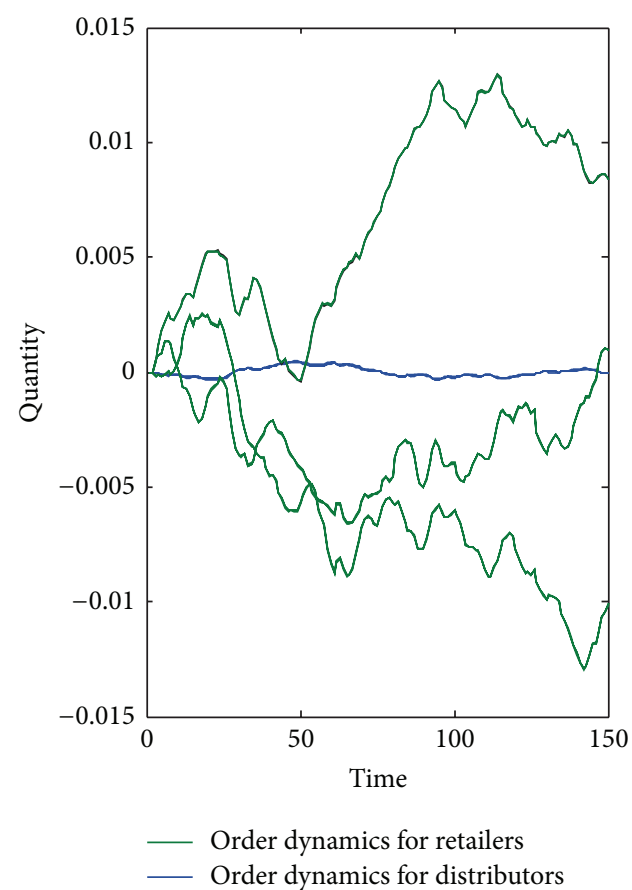

(b) Order curves under the second control way

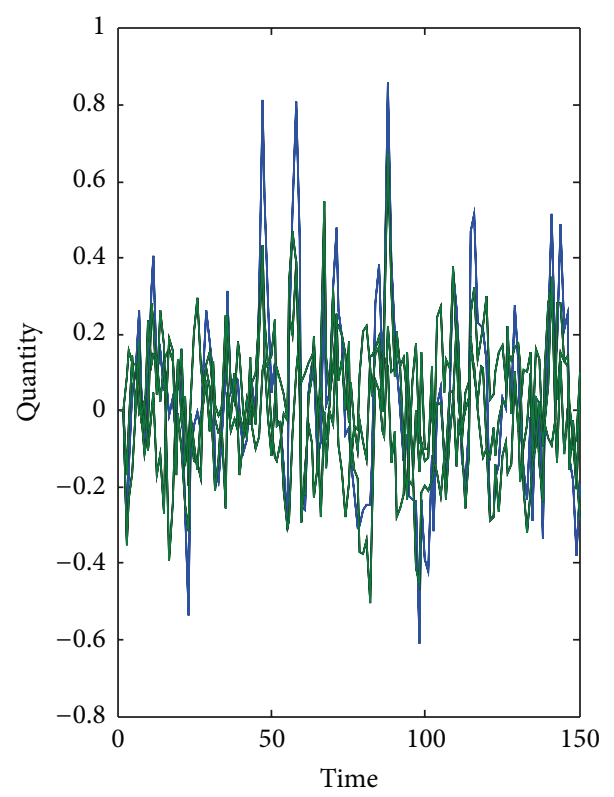

- Order dynamics for retailers

_ Order dynamics for distributors

(c) Order curves under the third control way

FIGURE 3: Dynamic curves of order under three different control ways.

TABLE 1: System performance under different control ways.

\begin{tabular}{lcccc}
\hline & $W_{b 1}$ & $W_{b 2}$ & $W_{s 1}$ & $W_{s 2}$ \\
\hline Control way 1 & $3.5782 \times 10^{3}$ & $6.2078 \times 10^{3}$ & $1.9027 \times 10^{-27}$ & 0.7570 \\
Control way 2 & $9.8163 \times 10^{-5}$ & $2.4236 \times 10^{-4}$ & $0.4375 \times 10^{3}$ & $1.1454 \times 10^{3}$ \\
Control way 3 & 0.2147 & 0.0810 & 0.0141 & 0.7890 \\
\hline
\end{tabular}




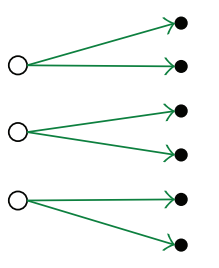

Structure 1

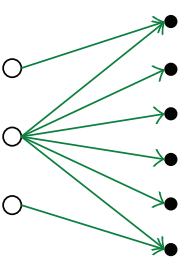

Structure 2

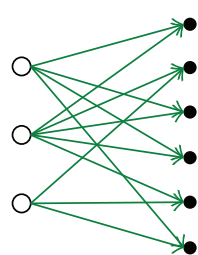

Structure 3

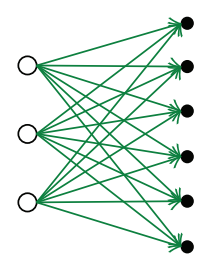

Structure 4

O Distributor

- Retailer

FIGURE 4: Four types of supply chain network structures.

In practice, both inventory and order fluctuations greatly enhance difficulties for supply chain management. For example, order fluctuations bring difficulties for arranging labor force and making full use of production capacity. Meanwhile, inventory fluctuations should be rigidly controlled for distributors because high costs will incur if items cannot be sold out timely. It will be better if we can find inventory rules that reduce both inventory and order fluctuations. From the third row in Table 1, we see that the third control way performs well in reducing both inventory and order fluctuations which have been decreased. Figures 2(c) and 3(c) further confirm the advantage of the third control way with the demand process $(20)$. In this sense, it reveals that the robust $H_{\infty}$ control method is highly effective in improving dynamics and robustness.

\subsection{Impact of Network Structure on Dynamics and Robust} Performance. The structure of supply chain network can be altered as a result of a lot of activities, such as adding new suppliers and extending distribution channels. These activities certainly impact the dynamics and robustness of supply chain network. For this purpose, the following study will be conducted with two concerns. We firstly consider the supply relationship, which is described by the supply relationship matrix $L$, and then consider the change of the number of nodes. Assume that $\chi_{i}=1$ and $\chi_{o}=1$ to consider both inventory and order fluctuations. To concentrate our attention on network structure, we will not take demand collaboration into account.

4.2.1. The Impact of Supply Relationship on System Performance. It is assumed that each retailer has the flexibility to choose its suppliers. Each retailer can place orders from multiple distributors; each retailer can also choose a single distributor as its supplier. Here we consider a supply chain network composed of 3 retailers and 6 distributors. Four types of supply are considered as shown in Figure 4 . The first structure is the simplest one, in which each retailer has only one supplier. The second structure is a distribution system with a major supplier. The latter two structures represent supply chain network with more complex supply relationships. The fourth structure, in which each retailer places orders from all the distributors, is the most complex structure in this study. The supply relationship matrix $L$ can be varied to represent different structures. The supply relationship matrixes for the four types of structures are given by

$$
\begin{aligned}
L_{1} & =\left[\begin{array}{llllll}
1 & 1 & 0 & 0 & 0 & 0 \\
0 & 0 & 1 & 1 & 0 & 0 \\
0 & 0 & 0 & 0 & 1 & 1
\end{array}\right], \\
L_{2} & =\left[\begin{array}{llllll}
1 & 0 & 0 & 0 & 0 & 0 \\
1 & 1 & 1 & 1 & 1 & 1 \\
0 & 0 & 0 & 0 & 0 & 1
\end{array}\right], \\
L_{3} & =\left[\begin{array}{llllll}
1 & 0 & 1 & 1 & 0 & 1 \\
1 & 1 & 0 & 1 & 1 & 0 \\
0 & 1 & 1 & 0 & 1 & 1
\end{array}\right], \\
L_{4} & =\left[\begin{array}{llllll}
1 & 1 & 1 & 1 & 1 & 1 \\
1 & 1 & 1 & 1 & 1 & 1 \\
1 & 1 & 1 & 1 & 1 & 1
\end{array}\right],
\end{aligned}
$$

where $L_{1}, L_{2}, L_{3}$, and $L_{4}$ are the supply relationship matrices for structure 1, structure 2, structure 3, and structure 4, respectively.

Using the optimization method introduced in Theorem 2, we could accordingly compute the minimal values of the robust metric $W_{I}$ for the supply chain network under four different structures; they are 2.2396, 2.2691, 1.9519, and 1.8361. It is obvious that the structure of supply chain network has significant influences on dynamics and robustness.

We use the demand process (20) with $\rho=0.6$ to generate demand sequences for retailers to observe the dynamics of order and inventory. The order dynamics of the three distributors are illustrated in Figure 5. Figure 5 shows that, compared with structure 1 and structure 2, structure 3 and structure 4 improve the dynamics for the three distributors. It means that complex supply chain network structure might help reduce order dynamics, namely, reducing the bullwhip effect. However, in the practice, we should consider other factors, such as distance between two nodes and information sharing costs. As the distance is increased, the transportation cost might be greatly increased. The second structure, which reflects a multiple-retailer system, results in high order fluctuations. In fact, too many downstream nodes can increase the risk of shortage, which has been recognized as one of 


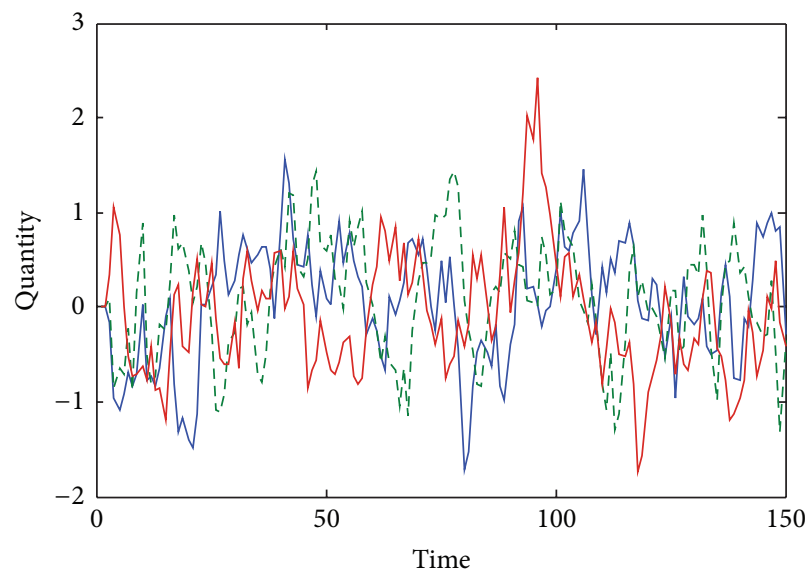

(a) Order dynamics of distributors under structure 1

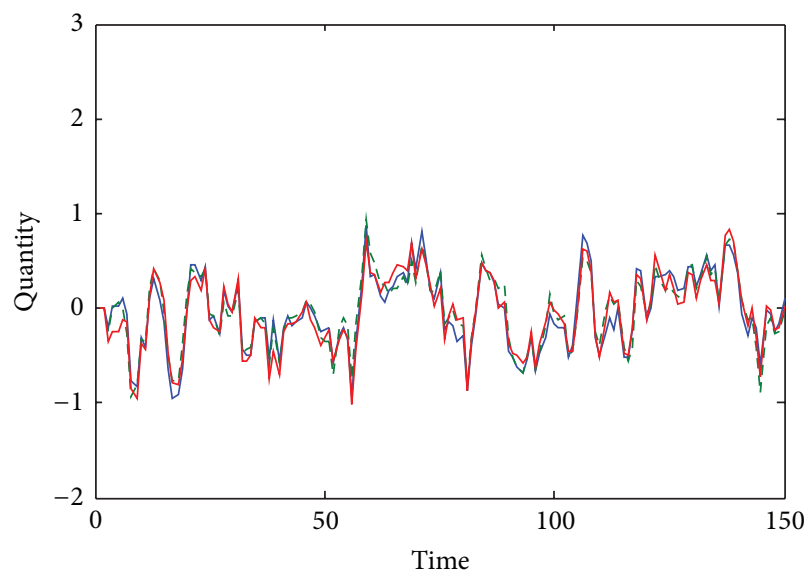

(c) Order dynamics of distributors under structure 3

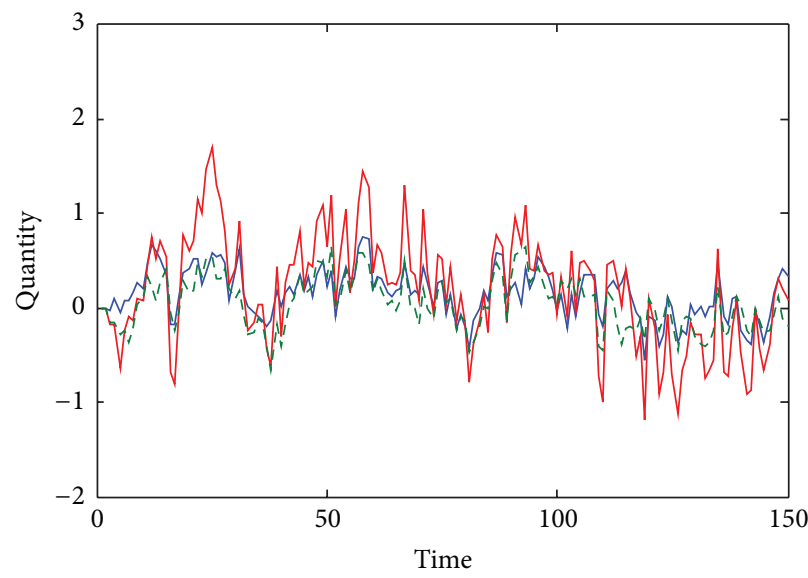

(b) Order dynamics of distributors under structure 2

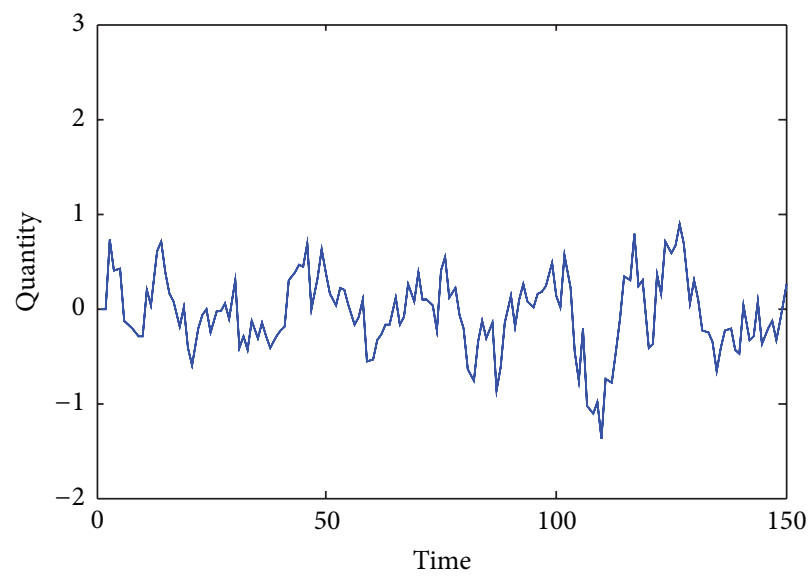

(d) Order dynamics of distributors under structure 4

FIGURE 5: Order dynamics under different structures of supply chain network.

the main causes of bullwhip effect [6], in the face of limited supply resources. Furthermore, since all the retailers should satisfy uncertain demands from external environment, too many retailers largely increase the uncertainties for the whole network and further lead to poor performance.

4.2.2. The Impact of the Number of Nodes on Robust Performance. As the supply chain network is hierarchical, we can change the number of upstream nodes or downstream nodes. Here we consider two cases:

(i) Case 1: increasing the number of distributors.

(ii) Case 2: increasing the number of retailers.

We assume that there exist two retailers in the first case and two distributors in the second case. The first case characterizes the supply chain system with multiple suppliers as the number of distributors increases. The second case represents distribution system with multiple retailers. It is obvious that increasing the number of distributors, as shown in Figure 6(a), has a positive effect on robustness improvement. This result can be explained where increasing the number of suppliers provides new purchasing channels or opportunities and thus the possibility of shortages will be lowered. From Figure 6(b), we see that increasing the number of retailers results in poor robust performance. This result confirms the result obtained before that a distribution system usually behaves poor on robustness performance.

From the above, it reveals that the structure of supply chain network is closely related to dynamics and robustness and thus seeking for optimal structures is essential for supply chain networks to achieve high economic benefits. Most importantly, our study adds new insights into the overestimated bullwhip effect problem [35, 36]. A recent study of US industry level data found that demand volatility does not increase as one moves up the supply chain [35]. The author observed that, in general, manufacturers do not have substantially greater demand volatility than retailers. However, traditional researches on the bullwhip effect believe that order fluctuations will be amplified stage by stage $[6,26]$. In other words, manufacturers, probably the most upstream nodes in a supply chain network, should experience the worst order fluctuations. It seems that the findings in [35] contradict the results in traditional researches. In this research, we found that a supply chain network with complex structures 


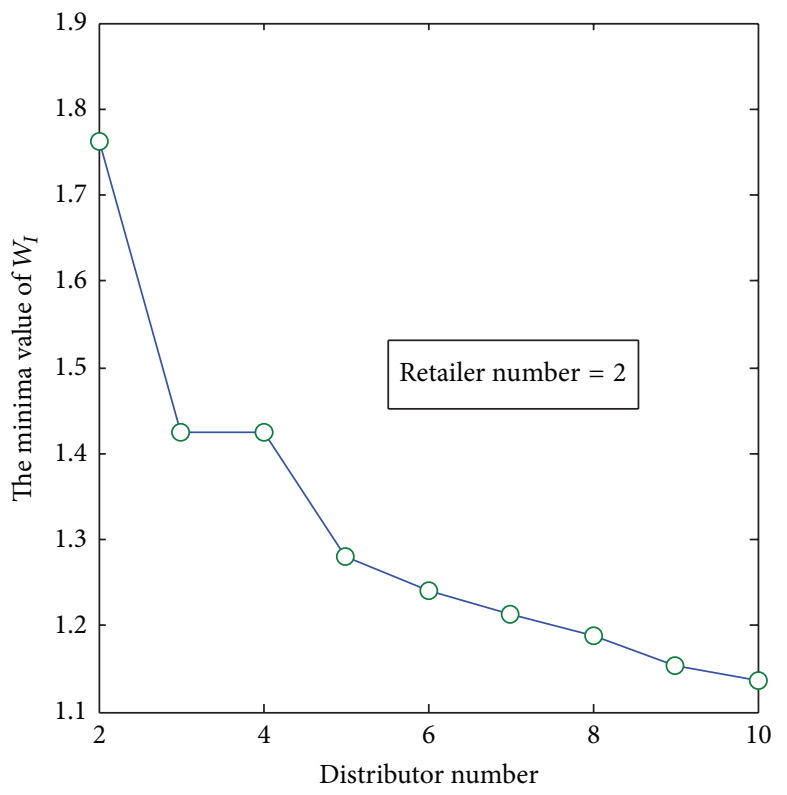

(a) Impact of distributor number on system performance

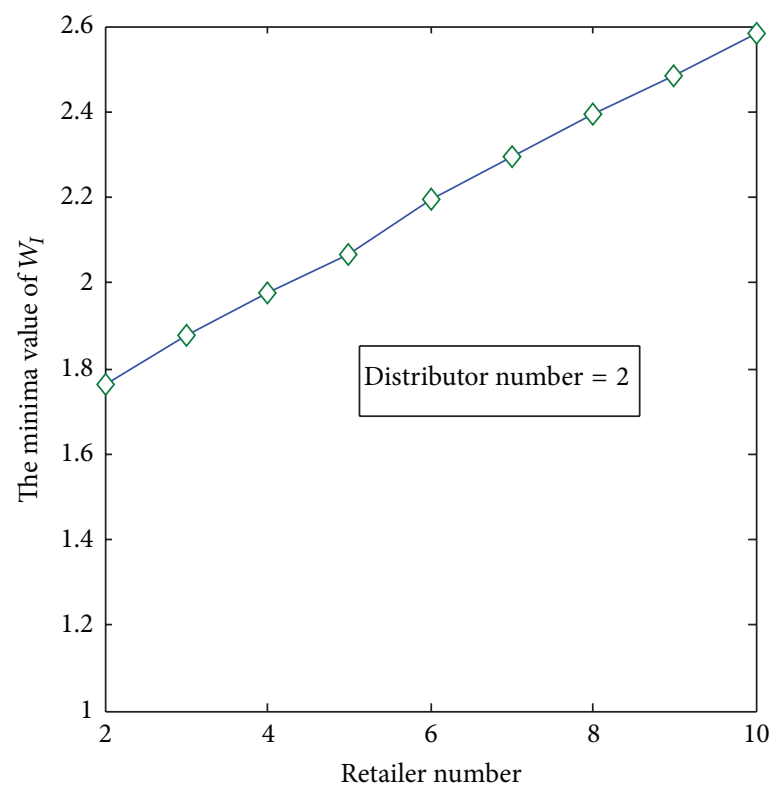

(b) Impact of retailer number on system performance

FIGURE 6: Impact of the number of nodes on robust performance.

behaves well in dynamics and robustness compared to simple networks. We also found that increasing the number of distributors contributes to the bullwhip mitigation. For this reason, we argue that the existing approaches that aim at quantifying the bullwhip effect neglect the network structure of supply chains. We believe that if we begin to study the bullwhip effect of supply chain network with the consideration of complex supply relationships and collaborations, not just serial supply chains, new results about the bullwhip effect might emerge.

\subsection{Impact of Demand Collaboration on Robust Performance.} As introduced, the collaboration mechanism among retailers is characterized by the collaboration matrix $H$. The retailer $j_{1}$ and retailer $j_{2}$ form their collaboration relationship with the parameter $\delta_{j_{1} j_{2}}, 0 \leq \delta_{j_{1} j_{2}} \leq 1$, which reflects the strength of collaboration. We will now consider a supply chain network with 3 retailers and 6 retailers. In many circumstances, one retailer tends to collaborate with a single retailer geographically close to it. To facilitate analysis, we assume that each retailer has only one collaboration partner. Then the corresponding collaboration matrix is represented as

$$
H=\left[\begin{array}{cccccc}
0 & \delta_{12} & 0 & 0 & 0 & 0 \\
\delta_{21} & 0 & 0 & 0 & 0 & 0 \\
0 & 0 & 0 & \delta_{34} & 0 & 0 \\
0 & 0 & \delta_{43} & 0 & 0 & 0 \\
0 & 0 & 0 & 0 & 0 & \delta_{56} \\
0 & 0 & 0 & 0 & \delta_{65} & 0
\end{array}\right],
$$

in which $\delta_{12}, \delta_{34}$, and $\delta_{56}$ are the collaboration parameters established by each pair of retailers. In addition, we assume that each retailer places order from all the suppliers. In other words, the values of all the elements of matrix $L$ are 1 . We also assume that $\chi_{i}=1$ and $\chi_{o}=1$ in order to consider overall performance. In this study, we will discuss three different collaborating scenarios:

(i) scenario 1: $\delta_{12}=\delta_{34}=\delta_{56}=0$ (without cooperation);

(ii) scenario 2: $\delta_{12}=\delta_{34}=\delta_{56}=0.25$ (mild cooperation);

(iii) scenario 3: $\delta_{12}=\delta_{34}=\delta_{56}=0.5$ (close cooperation).

Assume that retailer $j_{1}$ collaborates with retailer $j_{2}$, $\forall\left(j_{1}, j_{2}\right) \in\{(1,2),(3,4),(5,6)\}$; then their demand processes are assumed to be

$$
\begin{aligned}
& \widetilde{d}_{j_{1}}(t+1)=\rho \widetilde{d}_{j_{1}}(t)+(1-\rho) \varepsilon_{j_{1}}(t)+\eta_{j_{1}} \varepsilon(t), \\
& \widetilde{d}_{j_{2}}(t+1)=\rho \widetilde{d}_{j_{2}}(t)+(1-\rho) \varepsilon_{j_{2}}(t)+\eta_{j_{2}} \varepsilon(t),
\end{aligned}
$$

where $\rho=0.2, \eta_{j_{1}}, \eta_{j_{2}} \in\{-1,0,1\}$, with white noises $\varepsilon_{j_{1}}(t)$ and $\varepsilon_{j_{2}}(t)$ with mean 0 and variance 1 . A variety of auto- and cross-correlations among the demands can be represented by the selection of parameters. For example, the two demands may be independent of each other $\left(\eta_{j_{1}}=\eta_{j_{2}}=0\right)$, positively correlated $\left(\eta_{j_{1}}=\eta_{j_{2}}=1\right)$, or negatively correlated $\left(\eta_{j_{1}}=\right.$ $\left.-\eta_{j_{2}}=1\right)$.

The minimal values of the robust metric $W_{I}$ under the above three different collaboration scenarios can be computed by Theorem 2, which are 1.8361, 1.8686, and 1.8751. It shows that the collaboration behaviors have little impacts on the robustness improvement. However, we will see that the collaboration behaviors among retailers may mitigate 
TABLE 2: System performance under different collaboration scenarios.

\begin{tabular}{cccccc}
\hline & & $W_{b 1}$ & $W_{b 2}$ & $W_{s 1}$ & $W_{s 2}$ \\
\hline \multirow{3}{*}{ Scenario 1 } & $\eta_{j 1}=\eta_{j 2}=0$ & 1.0654 & 0.3993 & 0.0432 & 4.1398 \\
& $\eta_{j 1}=\eta_{j 2}=1$ & 4.3605 & 1.0635 & 0.1767 & 10.5216 \\
& $\eta_{j 1}=-\eta_{j 2}=1$ & 1.0423 & 1.0057 & 0.0422 & 10.5494 \\
\hline \multirow{3}{*}{ Scenario 2 } & $\eta_{j 1}=\eta_{j 2}=0$ & 1.0352 & 0.2482 & 0.0436 & 2.5674 \\
& $\eta_{j 1}=\eta_{j 2}=1$ & 4.3898 & 0.9023 & 0.1849 & 9.0700 \\
& $\eta_{j 1}=-\eta_{j 2}=1$ & 1.0253 & 0.3944 & 0.0431 & 4.2528 \\
\hline \multirow{2}{*}{ Scenario 3 } & $\eta_{j 1}=\eta_{j 2}=0$ & 1.0089 & 0.2084 & 0.0445 & 2.0619 \\
& $\eta_{j 1}=\eta_{j 2}=1$ & 4.1481 & 0.8425 & 0.1827 & 8.4610 \\
& $\eta_{j 1}=-\eta_{j 2}=1$ & 1.0093 & 0.2055 & 0.0445 & 2.0680 \\
\hline
\end{tabular}

the bullwhip effect for some special demand processes, as demonstrated in the following simulations. Under the demand processes formulated in (25), we can obtain the values of the four metrics, $W_{b 1}, W_{b 2}, W_{s 1}$, and $W_{s 2}$, via simulation with a length of 15000 periods, which are shown in Table 2. From Table 2, we see that the demand collaboration between retailers, or demand collaboration, has obviously reduced order and inventory fluctuations. Interestingly, when the values of collaboration parameters increase, the fluctuations of inventory and order decrease, and the reduction is the most significant for the case of negative cross-correlation. In addition, the reduction of inventory and order fluctuations for retailers is more obvious than distributors. This can be explained by the fact that the collaborations are established among retailers, not distributors.

In summary, collaborations among retailers might not contribute to robustness improvement; however, collaborations can reduce inventory and order fluctuations for some specific demand processes, especially for retailers. When [33] discussed the collaboration among retailers, they obtained similar results, in which they focus on order fluctuations in term of bullwhip effect. In this sense, our results confirm and also enrich the results in [33] using the robust $H_{\infty}$ control.

\section{Conclusions}

This paper has investigated the dynamics and robustness of a two-layer supply chain network constituted with multiple retailers and multiple distributors. A unified state space model is developed to characterize some basic characteristics of the supply chain network. Specifically, we describe different supply relationship with supply relationship matrix and consider one kind of demand collaboration mechanism among retailers, namely, demand diversion. As the nodes of supply chain network are heterogeneous, the dynamic equations for retailers and distributors are developed separately. Considering these characteristics enables us to investigate the influences of network structure and collaborations on dynamics and robustness.

It is well known that reducing order fluctuations usually increases inventory fluctuations [23], which tends to result in shortages and high levels of safety stock. This research, however, numerically showed that the robust $H_{\infty}$ control method based on the state space model has the advantage to reduce both inventory and order fluctuations for supply chain network. The simulation results show that complex supply relationships and demand collaborations among retailers contribute to the reduction of inventory and order fluctuations for unknown demand or specific demand. Collaborations among retailers might not improve the robustness of a supply chain network. However, collaborations can reduce inventory and order oscillations for some specific demand processes, especially for retailers. We argue that if we begin to study the bullwhip effect of supply chain network with the consideration of complex supply relationships and collaborations, new results about the bullwhip effect might emerge.

Finally, it is worthwhile to point out that the investigation of the dynamics and robustness of supply chain network, as we believe, is at the beginning stage. A lot of problems deserve future research. For example, if we consider more complex inventory rules, time delay problem will emerge. The relationship between system costs and dynamics is also an important topic because a supply chain network with complex supply relationships might incur high transportation costs.

\section{Conflict of Interests}

The authors declare that there is no conflict of interests regarding the publication of this paper.

\section{Acknowledgments}

This work was supported by the National Natural Science Foundation of China (no. 71401181 and no. 71502076) and the National Natural Science Foundation for Distinguished Scholars of China (no. 71125001). This work was also supported by MOE (Ministry of Education in China) Project of Humanities and Social Sciences (no. 14YJC630136 and no. 15YJC630008).

\section{References}

[1] G. Li, P. Ji, L. Y. Sun, and W. B. Lee, "Modeling and simulation of supply network evolution based on complex adaptive system and fitness landscape," Computers and Industrial Engineering, vol. 56, no. 3, pp. 839-853, 2009.

[2] S. M. Disney and D. R. Towill, "A discrete transfer function model to determine the dynamic stability of a vendor managed inventory supply chain," International Journal of Production Research, vol. 40, no. 1, pp. 179-204, 2002.

[3] C. F. Daganzo, "On the stability of supply chains," Operations Research, vol. 52, no. 6, pp. 909-921, 2004.

[4] Y. C. Wei, H. W. Wang, and C. Qi, "On the stability and bullwhip effect of a production and inventory control system," International Journal of Production Research, vol. 51, no. 1, pp. 154-171, 2013.

[5] Y. Wei, H. Wang, and C. Qi, "The impact of stock-dependent demand on supply chain dynamics," Applied Mathematical Modelling, vol. 37, no. 18-19, pp. 8348-8362, 2013.

[6] H. L. Lee, V. Padmanabhan, and S. Whang, "Information distortion in a supply chain: the bullwhip effect," Management Science, vol. 43, no. 4, pp. 546-558, 1997. 
[7] J. Dejonckheere, S. M. Disney, M. R. Lambrecht, and D. R. Towill, "Measuring and avoiding the bullwhip effect: a control theoretic approach," European Journal of Operational Research, vol. 147, no. 3, pp. 567-590, 2003.

[8] J. Dejonckheere, S. M. Disney, M. R. Lambrecht, and D. R. Towill, "The impact of information enrichment on the bullwhip effect in supply chains: a control engineering perspective," European Journal of Operational Research, vol. 153, no. 3, pp. 727-750, 2004.

[9] Y. Ouyang and C. Daganzo, "Characterization of the bullwhip effect in linear, time-invariant supply chains: some formulae and tests," Management Science, vol. 52, no. 10, pp. 1544-1556, 2006.

[10] J. D. Sterman, "Modeling managerial behavior: misperceptions of feedback in a dynamic decision making experiment," Management Science, vol. 35, no. 3, pp. 321-339, 1989.

[11] H. B. Hwarng and N. Xie, "Understanding supply chain dynamics: a chaos perspective," European Journal of Operational Research, vol. 184, no. 3, pp. 1163-1178, 2008.

[12] H. W. Wang, H. X. Liu, and J.-B. Yang, "Dynamic analysis of a two-stage supply chain-a switched system theory approach," International Journal of Advanced Manufacturing Technology, vol. 43, no. 1-2, pp. 200-210, 2009.

[13] S. C. Graves, "A single-item inventory model for a nonstationary demand process," Manufacturing \& Service Operations Management, vol. 1, no. 1, pp. 50-61, 1999.

[14] H. Sun and J. Wu, "Scale-free characteristics of supply chain distribution networks," Modern Physics Letters B, vol. 19, no. 17, pp. 841-848, 2005.

[15] R. Albert and A.-L. Barabási, "Statistical mechanics of complex networks," Reviews of Modern Physics, vol. 74, no. 1, pp. 47-97, 2002.

[16] A.-L. Barabási, R. Albert, and H. Jeong, "Mean-field theory for scale-free random networks," Physica A, vol. 272, no. 1-2, pp. 173-187, 1999.

[17] S. H. Strogatz, "Exploring complex networks," Nature, vol. 410, no. 6825, pp. 268-276, 2001.

[18] H. Su, G. Jia, and M. Z. Q. Chen, "Semi-global containment control of multi-agent systems with intermittent input saturation," Journal of the Franklin Institute, vol. 352, no. 9, pp. 3504-3525, 2015.

[19] H. S. Su, M. Z. Q. Chen, and G. R. Chen, "Robust semiglobal coordinated tracking of linear multi-agent systems with input saturation," International Journal of Robust and Nonlinear Control, vol. 25, no. 14, pp. 2375-2390, 2015.

[20] H.-S. Su and M. Z. Q. Chen, "Multi-agent containment control with input saturation on switching topologies," IET Control Theory \& Applications, vol. 9, no. 3, pp. 399-409, 2015.

[21] C. S. Lalwani, S. M. Disney, and D. R. Towill, "Controllable, observable and stable state space representations of a generalized order-up-to policy," International Journal of Production Economics, vol. 101, no. 1, pp. 172-184, 2006.

[22] R. Sipahi and I. I. Delice, "Stability of inventory dynamics in supply chains with three delays," International Journal of Production Economics, vol. 123, no. 1, pp. 107-117, 2010.

[23] S. M. Disney, D. R. Towill, and W. Van de Velde, "Variance amplification and the golden ratio in production and inventory control," International Journal of Production Economics, vol. 90, no. 3, pp. 295-309, 2004.

[24] K. Hoberg, J. R. Bradley, and U. W. Thonemann, "Analyzing the effect of the inventory policy on order and inventory variability with linear control theory," European Journal of Operational Research, vol. 176, no. 3, pp. 1620-1642, 2007.

[25] K. Hoberg, U. W. Thonemann, and J. R. Bradley, "Analyzing the effect of inventory policies on the nonstationary performance with transfer functions," IIE Transactions, vol. 39, no. 9, pp. 911924, 2007.

[26] F. Chen, Z. Drezner, J. K. Ryan, and D. Simchi-Levi, “Quantifying the bullwhip effect in a simple supply chain: the impact of forecasting, lead times, and information," Management Science, vol. 46, no. 3, pp. 436-443, 2000.

[27] Y. Ouyang, "The effect of information sharing on supply chain stability and the bullwhip effect," European Journal of Operational Research, vol. 182, no. 3, pp. 1107-1121, 2007.

[28] E. K. Boukas, "Manufacturing systems: LMI approach," IEEE Transactions on Automatic Control, vol. 51, no. 6, pp. 1014-1018, 2006.

[29] T. Nagatani and D. Helbing, "Stability analysis and stabilization strategies for linear supply chains," Physica A: Statistical Mechanics and its Applications, vol. 335, no. 3-4, pp. 644-660, 2004.

[30] S. Cannella and E. Ciancimino, "On the bullwhip avoidance phase: supply chain collaboration and order smoothing," International Journal of Production Research, vol. 48, no. 22, pp. 6739-6776, 2010.

[31] D. Helbing, "Modelling supply networks and business cycles as unstable transport phenomena," New Journal of Physics, vol. 5, pp. 90.1-90.28, 2003.

[32] B. Scholz-Reiter, S. Dashkovskiy, M. Görges, and L. Naujok, "Stability analysis of autonomously controlled production networks," International Journal of Production Research, vol. 49, no. 16, pp. 4857-4877, 2011.

[33] Y. Ouyang and X. Li, "The bullwhip effect in supply chain networks," European Journal of Operational Research, vol. 201, no. 3, pp. 799-810, 2010.

[34] R. Dominguez, S. Cannella, and J. M. Framinan, "On bullwhiplimiting strategies in divergent supply chain networks," Computers \& Industrial Engineering, vol. 73, no. 1, pp. 85-95, 2014.

[35] G. P. Cachon, T. Randall, and G. M. Schmidt, "In search of the bullwhip effect," Manufacturing \& Service Operations Management, vol. 9, no. 4, pp. 457-479, 2007.

[36] E. Sucky, "The bullwhip effect in supply chains-an overestimated problem?" International Journal of Production Economics, vol. 118, no. 1, pp. 311-322, 2009.

[37] J. H. Kim and H. B. Park, " $H_{\infty}$ state feedback control for generalized continuous/discrete time-delay system," Automatica, vol. 35, no. 8, pp. 1443-1451, 1999. 


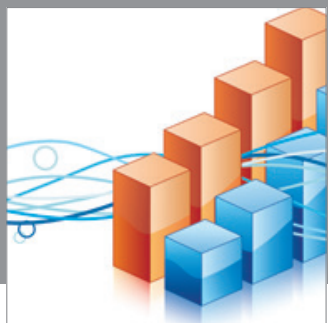

Advances in

Operations Research

mansans

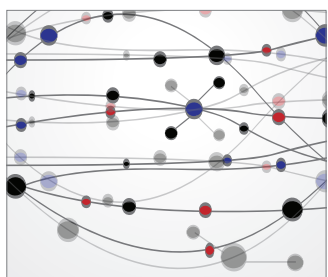

The Scientific World Journal
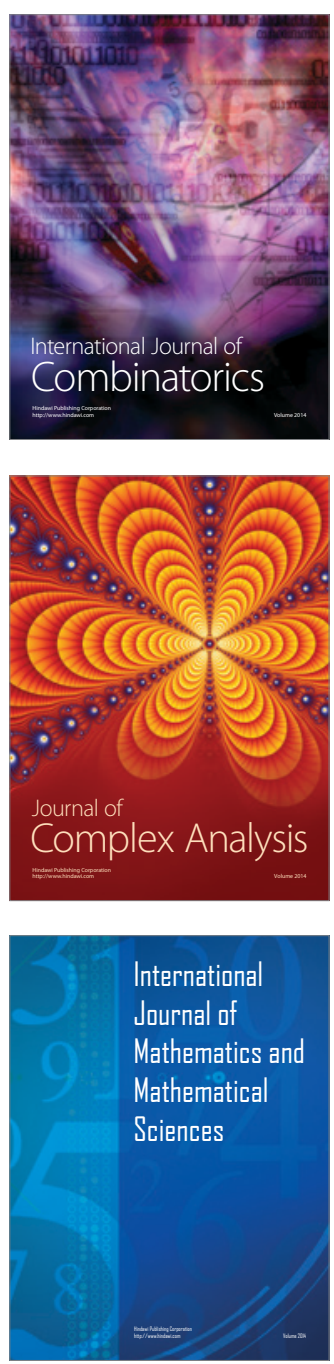
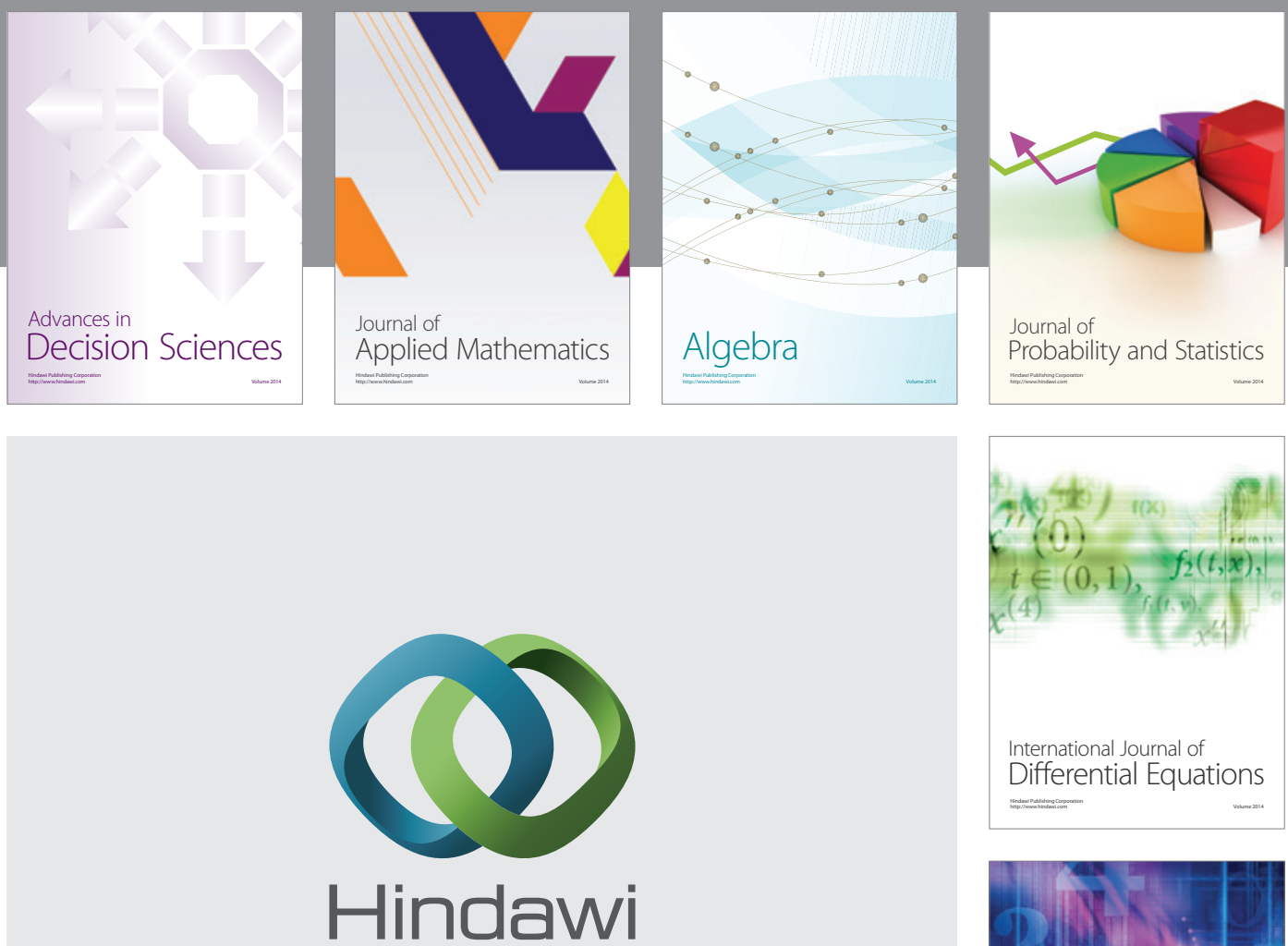

Submit your manuscripts at http://www.hindawi.com
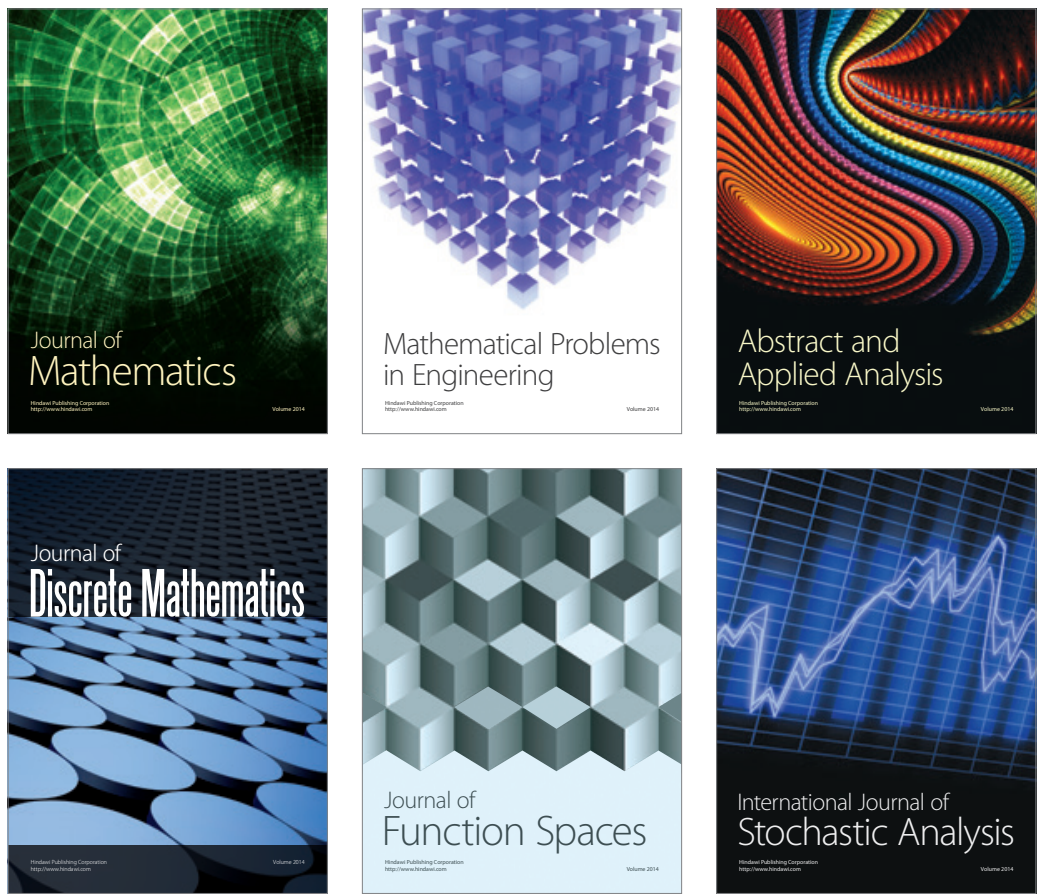

Journal of

Function Spaces

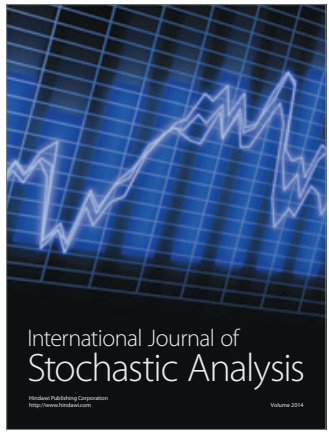

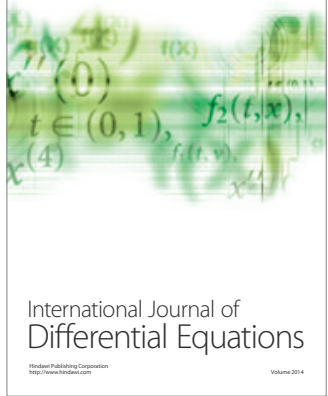
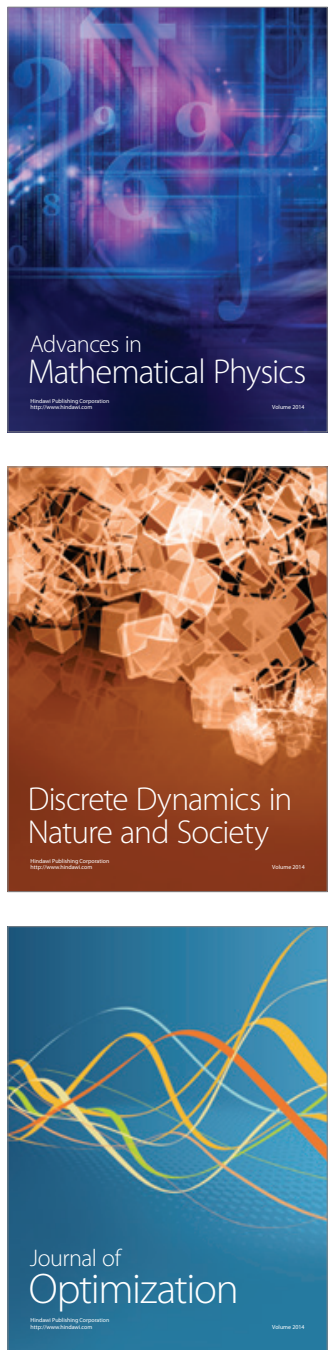